\title{
Inter-arterial course of left coronary artery in a case of non-specific chest pain
}

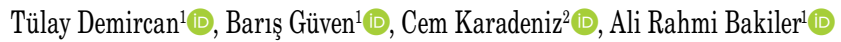 \\ ${ }^{1}$ Department of Pediatric Cardiology, Tepecik Training and Research Hospital, Izmir, Turkey \\ ${ }^{2}$ Department of Pediatric Cardiology, Katip Celebi University, School of Medicine, Izmir, Turkey
}

Received: November 27, 2018 Accepted: December 10, 2018 Published online: April 24, 2019

\begin{abstract}
A 17-year-old female presented with a history of short and sharp chest pain which was not exacerbated by effort for one year. Computed tomography angiography revealed a left coronary artery arising from the right coronary sinus with inter-arterial compression. In conclusion, computed tomography angiography can give excellent information about the anomalous origin and course. A high index of suspicion is needed in the diagnosis of coronary artery anomalies with an insidious clinical course.
\end{abstract}

Keywords: Congenital, coronary artery anomalies, left main coronary artery.

Coronary artery anomalies are rare in the general population and usually an incidental finding during coronary angiography. In the literature, the diagnosis of coronary artery anomalies is usually based on angiography or autopsy. Imaging modalities including computed tomography (CT) and magnetic resonance (MR) angiography provide excellent information about the course of coronary arteries.

Herein, we report an adolescent case of an interarterial course of the left coronary artery (LCA) in the light of literature data.

\section{CASE REPORT}

A 17-year-old female presented with a history of chest pain for one year. Chest pain was short and sharp and not exacerbated by effort. Her medical history was non-specific and her family history revealed a sudden cardiac death two months ago in her father aged 42 years.

Physical examination was normal including blood pressure, heart rate, and heart sound. Chest X-ray and electrocardiogram were also normal. Routine biochemistry including troponin I and lipid profile was not remarkable. Coronary artery anomaly was suspected based on echocardiography findings (Figure 1). Therefore, coronary CT angiography was performed. Coronary CT angiography showed the anomalous origin of the LCA from the right coronary sinus (Figure 2) and courses between the aorta and pulmonary artery which is divided into the left anterior descending artery (LAD) and left circumflex artery ( $\mathrm{LCx}$ ) (Figures 3). The LAD appeared to have a normal course. However, the LCx showed a course anteriorly to the left ventricle rather than the

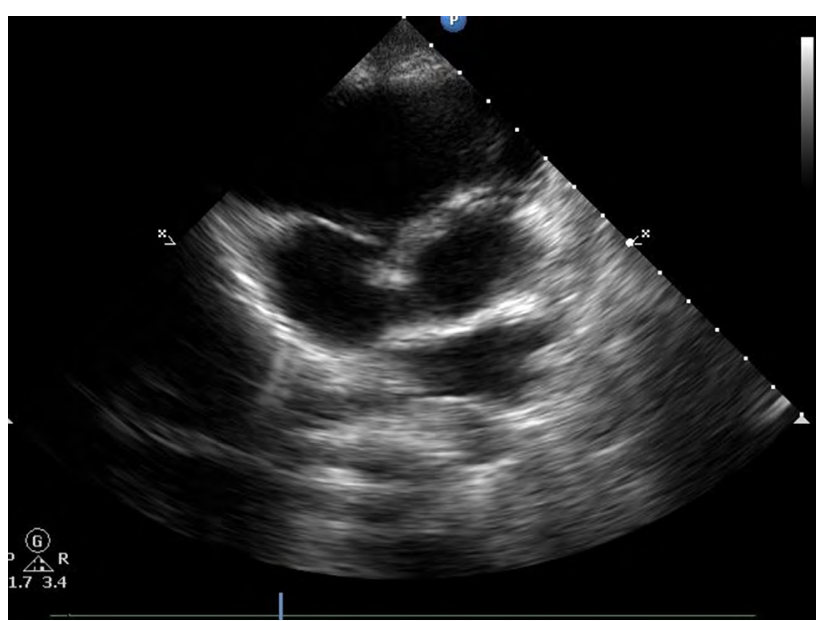

Figure 1. Echocardiography showing a suspected anomalous origin of left coronary artery.

Corresponding author: Tülay Demircan, MD. Tepecik Eğitim ve Araştırma Hastanesi, Çocuk Kardiyoloji Bölümü, 35180 Yenişehir, İzmir, Turkey.

Tel: +90 505 - 7538760 e-mail: tulay.sirin@hotmail.com

\section{Citation:}

Demircan T, Güven B, Karadeniz C, Bakiler AR. Inter-arterial course of left coronary artery in a case of non-specific chest pain. Cardiovasc Surg Int 2019;6(1):23-25. 


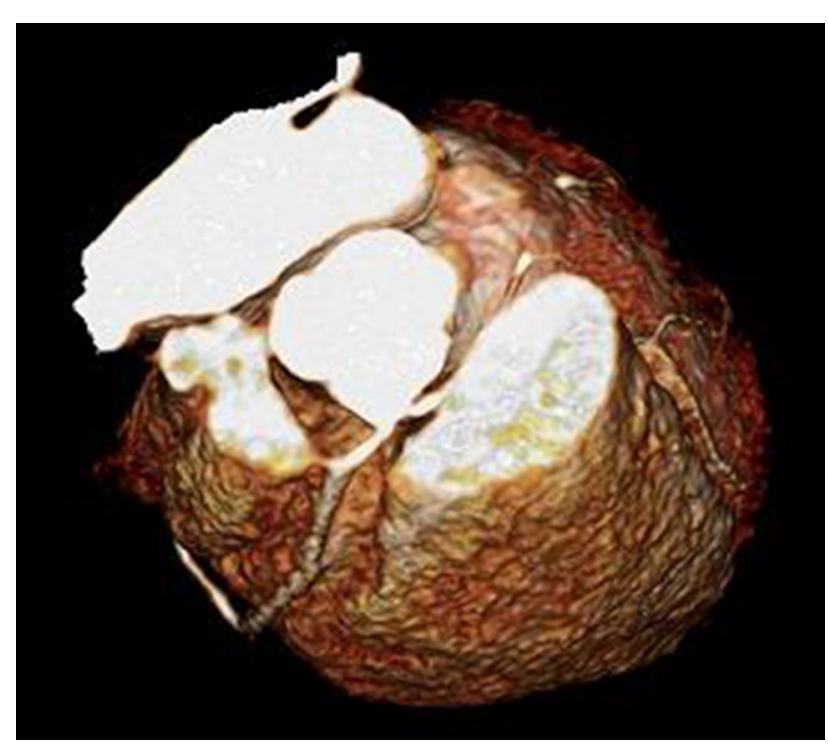

Figure 2. Coronary computed tomography angiography showing anomalous origin of left coronary artery from right coronary sinus.

atrioventricular groove. On exercise test, she remained asymptomatic and tolerated exercise test using the standard modified Bruce protocol. Surgical repair was decided due to the inter-arterial course of the left main coronary artery (LMCA). However, her parents are still indecisive about the surgical repair.

\section{DISCUSSION}

In this article, we report an interesting case of inter-arterial course of LCA originating from the right coronary sinus. Although the multi-detector CT provided excellent information about the origin and inter-arterial course of coronary artery, echocardiography is also helpful to detect such suspicious cases.

The incidence of congenital coronary anomalies ranges between 1 and $5 \%$ undergoing coronary angiography and $0.3 \%$ in autopsy series. ${ }^{[1,2]}$ Echocardiographic studies in pediatric population reported an incidence of $0.3 \% .^{[3]}$ Potentially serious coronary anomalies include ectopic coronary origin from the pulmonary artery, ectopic coronary origin from the opposite sinus, single coronary artery, and coronary fistula. ${ }^{[1]}$ Our patient had LCA originating from right sinus. The pattern of single or common ostium is considered to represent single coronary artery, as in our case.

Four anatomical variants have been described according to the course of the LMCA to the left side of the heart in single coronary artery arising from the right coronary sinus: (i) anterior: LMCA courses anteriorly to the right ventricular outflow tract; (ii) inter-arterial: LMCA passes between the great vessels; (iii) septal: LMCA has an intramyocardial septal course; and
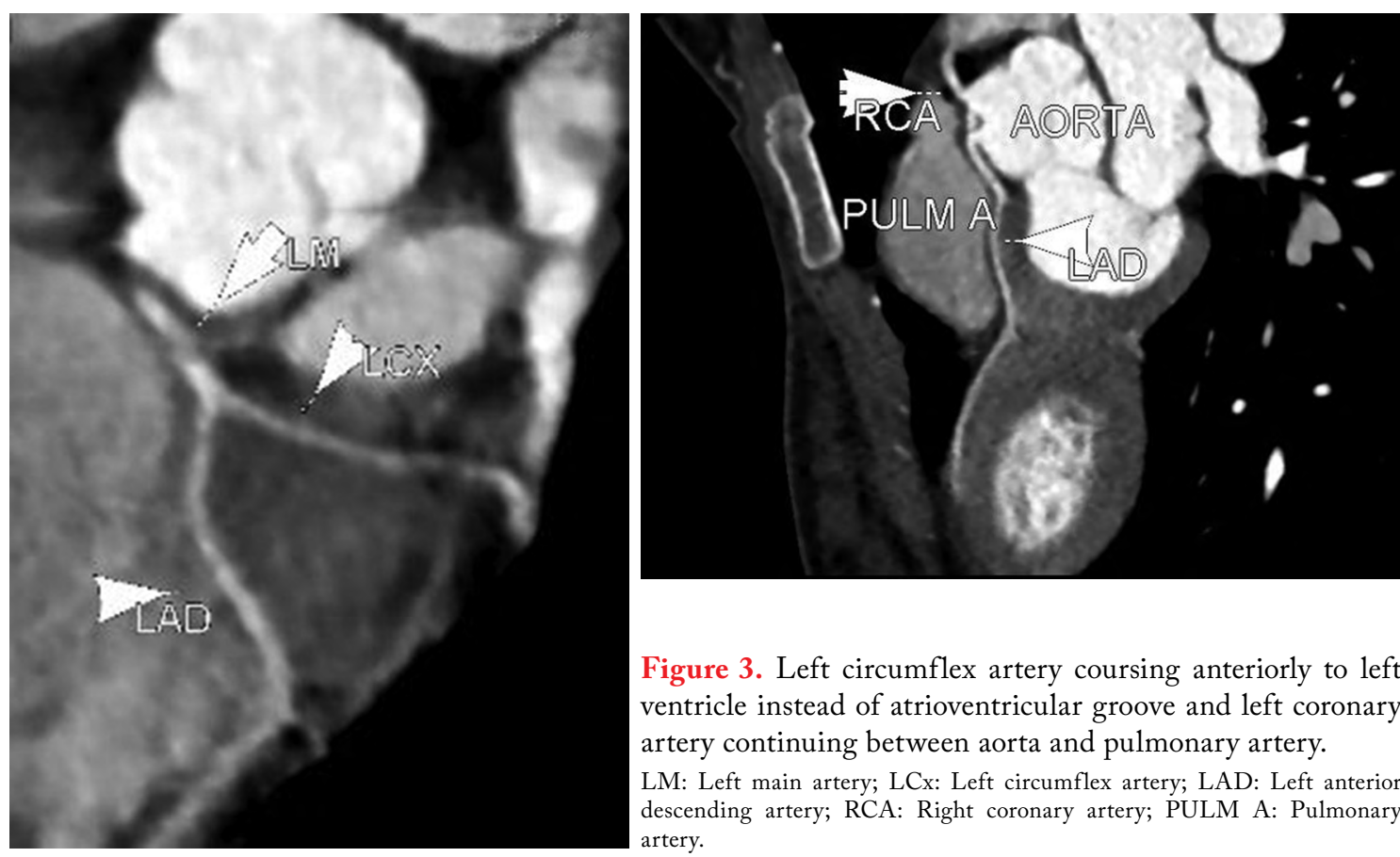

Figure 3. Left circumflex artery coursing anteriorly to left ventricle instead of atrioventricular groove and left coronary artery continuing between aorta and pulmonary artery.

LM: Left main artery; LCx: Left circumflex artery; LAD: Left anterior descending artery; RCA: Right coronary artery; PULM A: Pulmonary artery. 
(iv) posterior: LMCA courses posteriorly behind the aorta in the inferoposterior direction. ${ }^{[4]}$ Our patient had an inter-arterial variant. The incidence of inter-arterial variant ranges between 0.03 and $0.05 \% .{ }^{[1]}$ However, the inter-arterial course has been known as a cause of sudden cardiac death. Ischemia or sudden cardiac death are thought to occur due to the vascular kinking or compression. According to the most common postulated hypothesis, exercise results in enlargement of the aorta, which obstructs the acutely angulated slitlike orifice of the LMCA. ${ }^{[1]}$ Van Camp et al ${ }^{[5]}$ reported that coronary anomalies accounted for $11.8 \%$ of deaths in high school and college athletes. In addition, the Sudden Death Committee of the American Heart Association states that coronary anomalies account for $19 \%$ of deaths in athletes. ${ }^{[6]}$ In a study concerning death in young athletes with coronary anomalies arising wrong sinus, premonitory symptoms including chest pain and syncope were substantially rare, and electrocardiography and exercise tests were within normal limits in most cases. ${ }^{[7]}$

Echocardiography is essential in the diagnosis of coronary anomalies. However, it is imperative to define the course of coronary arteries to predict prognosis. Coronary angiography may cause some misinterpretations in cases with coronary anomalies. Therefore, imaging methods such as CT or MR angiography have been suggested. ${ }^{[4]}$ Multi-detector $\mathrm{CT}$ offers an excellent delineation of the LCA origin and provides the surgeon with a clear image of course of anomalous coronary artery. Therefore, we did not use conventional angiography in our case. Although patients are commonly asymptomatic, surgical repair is recommended, particularly after 10 years of age. ${ }^{[8]}$

In conclusion, coronary anomalies can be lethal during or shortly after vigorous physical activity, typically in young individuals. Diagnosis of coronary artery anomalies requires a high index of suspicion. Although echocardiography is useful, computed tomography angiography provides an excellent information about the coronary anomalies, as in our case.

\section{Declaration of conflicting interests}

The authors declared no conflicts of interest with respect to the authorship and/or publication of this article.

\section{Funding}

The authors received no financial support for the research and/or authorship of this article.

\section{REFERENCES}

1. Yamanaka O, Hobbs RE. Coronary artery anomalies in 126,595 patients undergoing coronary arteriography. Cathet Cardiovasc Diagn 1990;21:28-40.

2. Labombarda F, Coutance G, Pellissier A, Mery-Alexandre C, Roule V, Maragnes P, et al. Major congenital coronary artery anomalies in a paediatric and adult population: a prospective echocardiographic study. Eur Heart J Cardiovasc Imaging 2014;15:761-8.

3. Hauser M. Congenital anomalies of the coronary arteries. Heart 2005;91:1240-5.

4. Angelini P. Novel imaging of coronary artery anomalies to assess their prevalence, the causes of clinical symptoms, and the risk of sudden cardiac death. Circ Cardiovasc Imaging 2014;7:747-54.

5. Van Camp SP, Bloor CM, Mueller FO, Cantu RC, Olson HG. Nontraumatic sports death in high school and college athletes. Med Sci Sports Exerc 1995;27:641-7.

6. Maron BJ, Thompson PD, Puffer JC, McGrew CA, Strong WB, Douglas PS, et al. Cardiovascular preparticipation screening of competitive athletes. A statement for health professionals from the Sudden Death Committee (clinical cardiology) and Congenital Cardiac Defects Committee (cardiovascular disease in the young), American Heart Association. Circulation 1996;94:850-6.

7. Basso C, Maron BJ, Corrado D, Thiene G. Clinical profile of congenital coronary artery anomalies with origin from the wrong aortic sinus leading to sudden death in young competitive athletes. J Am Coll Cardiol 2000;35:1493-501.

8. Frommelt PC, Frommelt MA. Congenital coronary artery anomalies. Pediatr Clin North Am 2004;51:1273-88. 